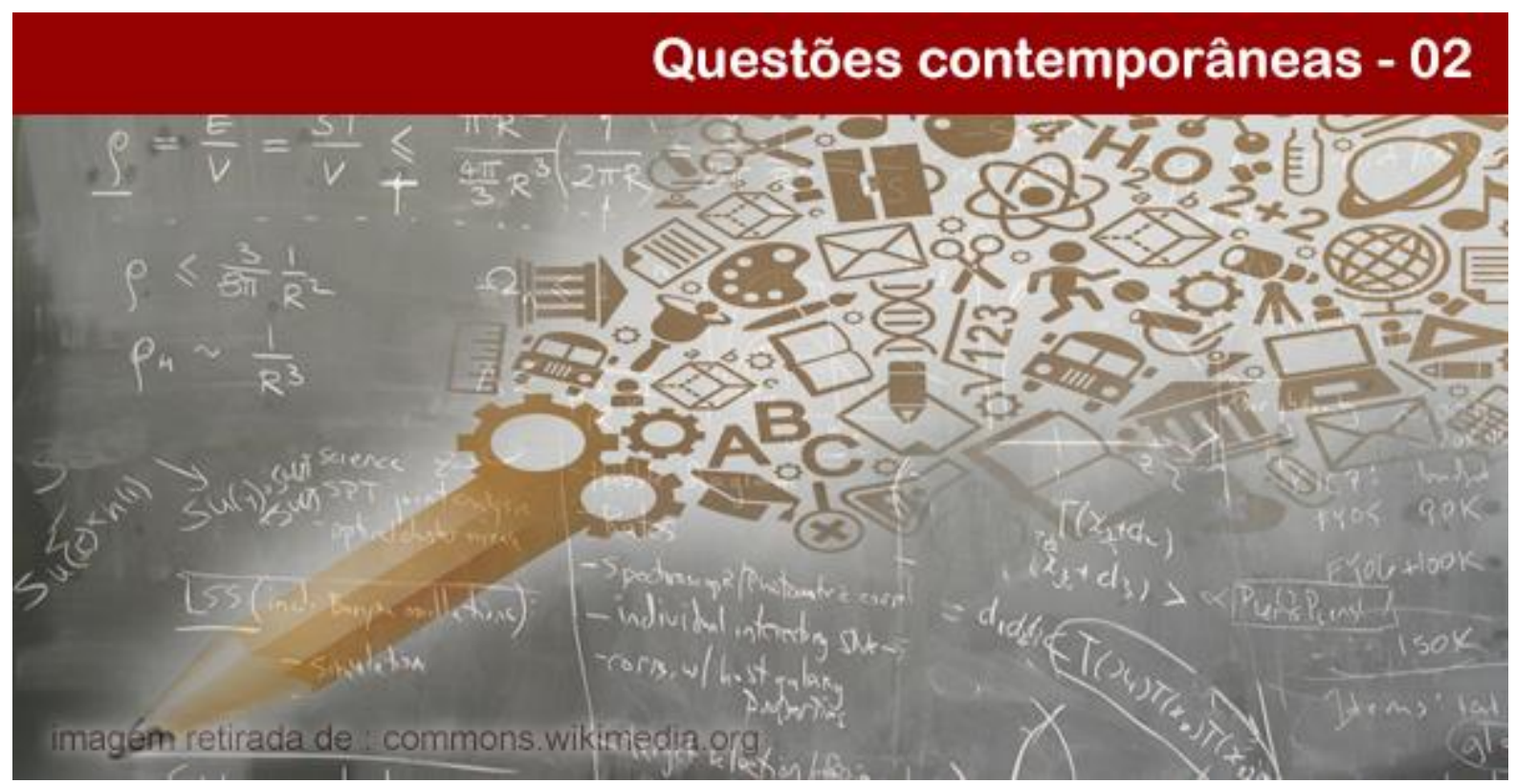

\title{
TROPEÇOS, ARRANHÕES E ARTIMANHAS NA ESCOLA ESBURACADA
}

\section{Beatriz Adura Martins}

Doutora em Psicologia pelo Programa de Pós-Graduação em Psicologia da Universidade Federal Fluminense. Supervisora Clinico-Institucional da Rede de Saúde Mental do Município do Rio de Janeiro. E-mail: biaadura@gmail.com.

\section{Luan Carpes Barros Cassal}

Psicólogo da Secretaria Municipal de Educação e Cultura de Itaboraí (RJ). Professor do Instituto de Psicologia da Universidade Federal do Rio de Janeiro. Doutorando do Programa de Pós-Graduação em Psicologia da Universidade Federal Fluminense.

Resumo: Uma escola e nossas apostas pedagógicas são colocadas em análise a partir da vontade de um menino: ele queria se chamar Samuel. O Menino, a professora e o supervisor vão tatear o chão de escola de uma cidade na região metropolitana do Rio de Janeiro. As singularidades deste território geográfico invadem seus corpos assim como a escola que é habitada por Samuel e outras alunas e alunos da educação básica brasileira. Samuel coloca questões para a escola e sua professora de geografia não consegue achar respostas. Professora, Menino e supervisor se encontrarão apresentando outros possíveis para uma pedagogia que mais sufoca do que faz viver. Guimarães Rosa, Benjamin, Blanchot e Louro nos auxiliarão na perspectiva desta experiência educacional.

Palavras-Chave: Corpo. Escola. Infância.

\section{STUMBLES, SCRATCHES AND TRICKS AT THE BUMPY SCHOOL}

Abstract: A school and our teaching bets are placed under review from the will of a boy:he wanted his name was Samuel. The teacher, the Boy and the supervisor will grope the floor of a school in Rio de Janeiro's suburb. The singularities of this geographic territory invade their bodies as well the school that is inhabited by Samuel and other girls and boys students of brazilian basic education. Samuel poses questions to the school and his geography teacher can not find answers. Teacher, Boy and supervisor will meet other potential presented for a pedagogy that suffocates more than makes living. Guimarães Rosa, Benjamin, Blanchot and Louro will assist us in this educational experience.

Keywords: Body. School. Childhood.

\section{POLÊM!CA | Revista Eletrônica da Uerj}




\section{Chegando na Escola: Tropeços}

Ela chegava com certa curiosidade àquele município que estava em pleno desenvolvimento. O sol castigava os corpos tampados por panos pesados naquela promissora cidade da região metropolitana do Rio de Janeiro. Alguns insistiam que ela era cidade de interior, roça, mas seus mais de 225 mil residentes já bagunçavam um pouco o velho cartãopostal da vida caipira. O petróleo ajudava a manchar a paisagem, agora mais quente que noutros tempos. Muito vai e vem. Casas indo ao chão e pequenos cubículos aprumados e mantidos por cimento do progresso mudavam o panorama local. A BR-101 já empilhava carros com seus IPI reduzidos que transportavam os solitários membros da 'nova classe média brasileira'.

Muita gente vai chegar. Sonhos. Ambições. Curiosos. Adultos. Crianças. Pessoas de todos os gêneros. Deste modo, prédios vão ocupando o cenário e fazendo ser necessário que os gestores locais se organizem para darem conta da cidade do futuro. Corre-corre administrativo e os educadores locais já pensavam em suas tarefas: Como manter ou aumentar o Índice de Desenvolvimento da Educação Básica (Ideb)? Como garantir a matrícula de crianças e adolescentes nas escolas? Como produzir uma escola que não reprove? Como cuidar de tanta gente?

Distante deste palco e com menos ar-condicionado, já com o transporte público devidamente precarizado, é que aquela mulher um pouco cabisbaixa se lançava na rodoviária da cidade. O bairro de destino localizava-se na região rural daquele município e também percebia os efeitos do progresso. Sentia seu alto índice de analfabetismo misturado a um calor insuportável no lombo dos citadinos, que em outros tempos sabiam até a época da colheita. A professora do ensino básico já chegava na unidade em que lecionava... Erradicação do analfabetismo. APROVADO. Universalização do atendimento escolar. APROVADO. Superação das desigualdades educacionais, com ênfase na promoção da cidadania e na erradicação de todas as formas de discriminação. APROVADO. Seus ombros pareciam pesados.

Melhoria da qualidade de educação. APROVADO. Formação para o trabalho e para a cidadania, com ênfase nos valores morais e éticos em que se fundamenta a sociedade. APROVADO. Promoção do princípio da gestão democrática da educação pública. 
APROVADO. Promoção humanística, científica, cultural e tecnológica do País. APROVADO. Seus passos já custavam.

Estabelecimento de material, aplicação de recursos públicos em educação como proporção do Produto Interno Bruto (PIB) que assegure atendimento às necessidades de expansão, com padrão de qualidade e equidade. APROVADO. Valorização dos profissionais da educação. APROVADO. Promoção dos princípios do respeito aos direitos humanos, a diversidade e a sustentabilidade socioambiental. APROVADO. Agora era a vez da respiração que parecia não encontrar ar.

A cada parágrafo aprovado das diretrizes que norteariam os próximos dez anos de política de Educação no País, aquela professora ficava mais corcunda. Só um olhar atento notava sua curvatura, pois ela não demostrava o peso, mas sentia. A aprovação do Plano Nacional de Educação (BRASIL, 2014) chegou a ela por meio de metas a serem atingidas e, em suas costas, a responsabilidade de ter que dar conta dos princípios morais e éticos que norteiam a sociedade - seja lá o que isso quer dizer.

Pernas bambas, pouco ar, e o pó da estrada de terra atrapalhavam a chegada da professora à Unidade de Ensino. Prédio velho, salas de aulas hiperlotadas e aquela criançada a deixaram um pouco tonta. Corpo pesado, a professora vai ao chão. Pode o chão fazer tremer a realidade posta?

\section{Os arranhões de um menino que não sabia}

Escutaram disciplinarmente o Hino Nacional, agora podiam seguir em fila para a sala de aula. Empurrão, pisadela no calcanhar, peteleco na orelha e 'tirar onda' do colega pelo seu time perdedor no domingo; todos acompanhavam a marcha inquieta dos alunos do sexto ano à aula de geografia. A diretora da escola olhava de longe a meninada se organizando para mais um início de ano letivo.

É fevereiro e o calor já se faz insuportável. Usar bermuda, camiseta, meia e tênis parece um castigo (quem foi mesmo que vestiu esses mestiços, querendo deles mais civilidade?). Um grupo pequeno ia de chinelo, não tanto pela revolta com os colonos europeus, mas, sobretudo, por fazer da sandália de dedo seu único calçado. 
A sala de aula era bem quente, fazendo jus aos termômetros da cidade. Ela era mais um município brasileiro dentre os quase seis mil municípios existentes em $2013^{1}$. Sabia que fazia parte das estáticas que apresentam uma educação desejante de melhorias. Entre 225 mil habitantes, 36 mil pessoas estavam matriculadas no ensino fundamental e 7.618, no ensino médio. Aquela relativamente pequenina escola da 'área rual' também teria que seguir as normativas da Política Nacional da Educação e seu lema de uma educação universal para a erradicação do analfabetismo e preocupada com a evasão escolar.

O barulho não se estancava e se ouvia o zunido da sala ao lado. Carteiras enfileiradas lembravam as crianças que teriam que se comportar. A professora já chegava na sala de aula pedindo silêncio, mas de pouco adiantava seu singelo suplício. Não paravam de falar. Era primeiro dia de aula e a professora recém-chegada na escola ainda estranhava o ambiente e os alunos que a desafiavam na sua insegurança de principiante.

Chamada. De nome em nome ia identificando seu alunado: Ana, Bianca, Carla, Daivdison, Eduardo, Fabio, Gilda, Henrique, Ismail, Joselen, Lunilda, Moser, Nyldson, Osmar, Paulínia, Queyti, Ronilson, Suelen, Tiago, Uira, Vini, Xênia e Zoe, Cleiton, Nunes, Aspasia, Glauria... Fim da chamada. E o barulho retorna. De longe uma criança tenta falar com a professora. Ela estava na fileira do meio, sentada na quarta carteira. Ao redor, sentavam quatro meninas: Carla, Gilda, Joselen e Xênia. Parecia que assim uma certa proteção estava garantida. Ela, no meio, fica com o braço estendido.

Depois de um tanto de tempo a professora olha e diz: "Agora que vi esse clube da Luluzinha, quero logo que esse grupinho se desfaça; mas vamos lá, diga!". "Professora", a voz titubeia em sair, a cabeça abaixa e o corpo, que pedia a força para uma batalha, tremia. "Professora, a senhora me chamou pelo nome errado". "Ora, só isso? Quanta novela, me diz: você não gosta de se chamar Lunilda é isso?”. “Isso!”, respirava com alívio pela compreensão da professora, atenta as brincadeiras infantis. "Me chamo Samuel". As meninas tomaram a frente e já desafiavam a professora. "Viu, não tem clube da Luluzinha, o Samuel não é menina", tomou a palavra Carla, a mais pimentinha.

$\mathrm{Na}$ casa de Zoe, coleguinha de Samuel, aos domingos ninguém ficava em casa. A família que morava perto da escola vivia unida, ganhavam um benefício do governo federal e podiam, assim, almejar atingir a média da renda per capita daquele território - que não

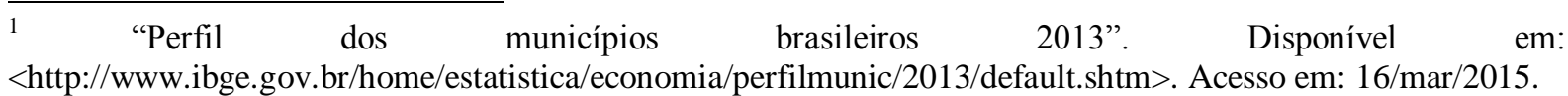


passava de $\mathrm{R} \$ 382,00$. Aos domingos precisavam agradecer pela melhora de vida nos últimos oito anos. Confiantes em Deus, sabiam que Ele era o único responsável por aquele milagre (quase) econômico. Rezavam intensamente pela Graça do Senhor. Aparentavam uma estável felicidade.

Na casa de Gilda, era um pouco diferente. A família também era usuária do Bolsa Família. Gilda é filha de Dorina, que está grávida de uma irmãzinha para ela, que por sua vez recebia os cuidados para sua gravidez no Sistema Único de Saúde a partir do Programa Federal Rede Cegonha. O pai de Gilda era conhecido na área, pois tocava viola com os amigos do bairro. O pai de Gilda fazia muita gente sambar. Ensinava para a menina que na vida tinha que batalhar pra não se perder em aventuras.

As casas que faziam proximidade com a escola eram muito diferentes entre si, muitos costumes, religiões, crenças, gostos e organização. Vini só conhecia sua mãe, mas não sabia o nome e o paradeiro de seu pai. Uira tinha pai e mãe na prisão, sua irmã aparecia para lhe buscar na escola e fazer sua comida; a noite, ganhava o dinheiro para sustentá-lo e isso o deixava com medo no escuro. Carla, a pimentinha, era filha do Pastor e sua mãe organizava a banda de música da Igreja, tinha um irmão que trabalhava para o tráfico da região. Samuel era filho de doméstica e bombeiro e, sempre, que dava acompanhava seu pai nas casas que ia fazer consertos. Samuel adorava a Baía de Guanabara e ver a novela com sua família.

Todo mundo na sala de aula. Mas ninguém com o corpo tão preparado para a batalha como Samuel. A batalha de Samuel era delicada, era bem magro, alguns machucados denunciavam embates antes de chegar a escola. A professora não titubeia: "Você é muito criança e não sabe o que está dizendo". Ele retruca "Só estou dizendo que me chamo Samuel”. Professora e Samuel se olham. Ela, com seu saber de adulta que garantia que criança é um ser em desenvolvimento. Ele, com seu saber de criança, que não sabia porque era tão estranho ser Samuel. Ruidoso silêncio.

Insuportável silêncio. Zoe puxa o coro aprendido com os adultos da igreja: "Sapatão! Sapatão! Sapatão". Carla, que frequentava a mesma igreja garante: "Zoe, Deus não julga, acolhe". Carla chega mais perto de Samuel e diz que na sua igreja ele seria aceito e que precisava rezar para se ver livre de pensamentos colocados pelas novelas que ele tanto gostava. Gilda olha tudo em sua quietude e, sem saber muito porque, lembra de um samba 
cantarolado por seu pai quando ela estava tristonha: "Segura o choro criança/vou te fazer um carinho/levando um samba de leve/nas cordas do meu cavaquinho"2.

A professora lembra que no ano de 2012 o Programa Escola Sem Homofobia fora vetado pelo Governo Federal e, com essa memória, se autorizou a seguir com a sua diretriz: "Lunilda, por favor, pare com esse desrespeito, não existe travesti com a sua idade". Lunilda é chamada, mas Samuel insiste: "Por que me chama de travesti? Só quero ser Samuel". A professora pede que fique em silêncio e retoma a aula.

Ouve-se a campainha do recreio. Lá se vão as pernas apressadas da meninada ansiosa por brincar. Zoe, Uira e um garoto da oitava série vão mexer com Samuel. Dão muita risada dele e as injúrias se apresentam nas bocas adestradas dos meninos que tudo sabiam: de sapatão, virou travesti e, de travesti, puta - tudo em uma escala evolutiva inquestionável. Samuel se encolhe, um pouco triste, mas com muita raiva. Seu corpo magro e cansado da guerra vai ao chão. Pode o chão fazer tremer a realidade posta?

\section{O supervisor precisava ver}

Acompanhando os carros e seus engarrafamentos cotidianos, chega na cidade o novo supervisor educacional. Morador de um grande centro urbano e formado por uma universidade de excelência, o educador tem enfim a possibilidade de colocar a prova suas teorias e técnicas de ponta. Seu corpo carregava a disciplina dos bancos escolares de nível superior e a responsabilidade dos títulos de pós-graduação. Atravessado por desejos, expectativas e a estabilidade do serviço público, cruzava as dezenas de quilômetros que separavam a metrópole daquela ainda cidade-dormitório em transformação.

Com a função de verificar o processo de aprendizagem e organizar a vida documental de crianças e adolescentes das escolas da rede pública, o supervisor ía para mais uma visita de rotina nas unidades de ensino. As demandas eram inúmeras, e pediam para que olhasse para todos os lados ao mesmo tempo. Veja Leninlton. Ele não tem laudo, mas tenho certeza de que precisa de remédios. Não é normal uma criança se comportar assim. Veja Thaís. Ela está há anos na alfabetização, não aprende nada. Veja Wesley. Seus irmãos mais velhos estudaram aqui. Eram iguaizinhos. A mãe não quer saber, só se interessa pelo Bolsa Família. Veja Fabiana. A mãe só chama ela de Roberta. Diz que Fabiana é o mesmo nome de uma tia que

${ }^{2}$ Referente ao samba de Paulinho da Viola: "Eu canto samba". 
abusou da menina, e não quer chamá-la pelo nome. Mas como eu vou alfabetizar se não é pelo nome dela? Veja Marcela. Veja Crispin. Veja Vanise. Veja Wilian.

Todas essas histórias enchiam o carro do supervisor de papéis, sua cabeça de ideias. Por que importa tanto a cor da caneta usada nos diários de classe? O porta-malas do carro se enche de papéis: cópias de documentos, livros didáticos e acadêmicos, inclusive sua ousada dissertação, termos de visita se misturavam às roupas para constantes mudanças de temperatura. O que ensinar quando falta água no bairro? Como a professora adoecida avalia seus alunos? Ele andava com o Estatuto da Criança e do Adolescente, a Lei de Diretrizes e Bases da Educação Nacional, as legislações estaduais e municipais e eventualmente algumas jurisprudências para orientar seu trabalho. Onde está a aprendizagem no meio dos papéis? O corpo daquele qualificado profissional lembra do não retorno da antiga supervisora, em licença médica. Os joelhos tremem e a respiração fica curta.

O supervisor estica as pernas cansadas da viagem, estala os joelhos, percebe certa dor nos braços, se faz atento, fuma um cigarro e entra na casa alugada onde funciona a escola para mais uma reunião de planejamento. Os olhos circulam cada canto, cada fresta, o suor que cai em seus olhos faz ele perceber a telha de zinco e lembrar do tal princípio pedagógico que tanto estudou. Um vento aparece, é produzido pela correria da criançada que sai em polvorosas confundindo ainda mais a sua visão. É aquele corre-corre, gritaria, circulação de cuidadores e seus pequenos, às vezes todos do mesmo tamanho.

Mais uma reunião pedagógica centrada nos informes e pactuações de calendário. $\mathrm{O}$ supervisor leva materiais para discutir a reformulação pedagógica, mas não reverbera naquele agrupamento. Seu corpo vibra intensamente com a possibilidade de construção coletiva, e o grupo o tempo todo escapa. A longa batalha por uma educação pública universal e de qualidade cobra seu preço daqueles corpos com até trinta anos de magistério.

No horário do almoço, todos parabenizam a jovem professora que irá se casar. Entre a merenda escolar, as bênçãos e os conselhos, as professoras querem saber mais sobre o supervisor. Ele conta sobre a universidade, a cidade e o bairro onde mora. E também de seu marido, com quem vive desde o fim da faculdade. O supervisor não consegue ver o que vem por aí, mas sente uma tempestade. Silêncio sufocante, seus olhos fraquejam insinuando olhar o chão. 
Susto e uma sequência de curiosidades e opiniões impedem que aquele olhar fraqueje. Precisa responder a tantas perguntas? Quem autorizou tanta gente a falar dele? A coordenadora pedagógica quer saber mais da reação da mãe dele. A professora de matemática pergunta a respeito do marido. A professora de informática se retira do refeitório. A professora de português diz que apoia a união estável de homossexuais, mas entende a adoção como um problema; afinal, a criança perde a referência de masculino e feminino com dois homens. Afirmam verdades que congelam a infância numa lógica gramatical.

Cochichos e olhares seguem após o almoço, o supervisor respira fundo e deixa o ar entrar, ora se defendendo, ora querendo entender tantas manifestações. A professora de artes pede pra ver uma foto do marido, e quer saber quem é o homem da relação. Também pergunta se ele já teve experiências com mulheres. O professor de educação física diz que tem uma irmã lésbica; já a professora de informática, que não suportaria um filho homossexual. Todos têm algo a dizer, e ainda mais a perguntar. Uma exigência de confissão e uma vontade de saber que já traz respostas prontas (FOUCAULT, 1988). Suas pós-graduações em gênero, sexualidade e diversidade e suas técnicas para abordar estes temas em sala de aula não foram o bastante; as pesquisas de campo com travestis e transexuais que abandonaram a escola por conta da discriminação não preparavam o corpo para aquele massacre; os dados de escolas com baixo rendimento escolar e altos índices de preconceito e discriminação entravam pelos seus olhos e ouvidos de um modo que seus formulários não registravam.

A semana segue, mas ele não escapa da diretora que o chama em sua sala. Ele precisa entender que a escola é um espaço para todos, mas que não precisa fazer o que ela chama de 'apologia ao homossexualismo'. Pois são educadores e têm uma responsabilidade muito grande com essas crianças. Além disso, não sabe como os responsáveis vão reagir. E diz estar satisfeita que o assunto está resolvido. O silêncio do supervisor continua a ser preenchido por afirmativas sobre sua vida, sobre a vida de todos. O silêncio não poupa seu olhar que nessa hora grita por ar.

O supervisor não vê mais suas teorias, técnicas e legislações. A militância em movimentos sociais cooptados pelo Estado endureceu suas práticas; pensava em denúncias e delegacias, mas qual o princípio pedagógico de tal ato em uma escola? Os históricos escolares careciam de reorganização. A professora de matemática pergunta sobre a pós que ele fez e pede indicação de materiais. As planilhas de aprovação e recuperação ainda não foram

\section{POLÊM!CA | Revista Eletronica da veri}


preenchidas. O inspetor de alunos lhe olha de cara feia. A turma de quinto ano precisa de uma nova data para o conselho de classe. A professora de português pede uma carona até a rodovia. Alguns alunos estão sem aula, porque o professor de inglês faltou. O calor, o barulho, o peso da mochila, tudo começa a ficar insuportável. O supervisor sente o massacre de ser sujeitado aos discursos que passam a anteceder sua própria existência e perder o direito a autoria de si.

Ouve dois alunos brigando. Se batem, aos gritos de "Viado tem que morrer!". O supervisor tenta separar, mas a confusão está instaurada. Um empurrão vem sabe-se lá de onde, os papéis voam, o corpo se desmonta no pátio, parte do lixo que se acumula pelos cantos. Pode o chão fazer tremer a realidade posta?

\section{Afivelando o cinto de segurança: cuidando dos buracos}

O menino fremia no arcoçôo, alegre de se rir para si, confortavelzinho, com um jeito de folha a cair. A vida podia às vezes raiar numa verdade extraordinária. Mesmo o afivelarem-lhe o cinto de segurança virava forte afago, de proteção, e logo novo senso de esperança: ao não sabido, ao mais. Assim um crescer e desconter-se - certo como o ato de respirar - o de fugir para o espaço em branco. O Menino. (ROSA, 1974a, p.21).

Samuel só queria ser Menino. O supervisor diferia, não queria respeito, queria existência (SILVA, 2002). A professora temia a forma corcunda que lhe memorava velhas bruxas. Samuel, a professora e o supervisor se encontravam no chão da escola. Atentos aos arranhões do tombo, eles precisam se cuidar, mas a forma do encontro fazia tremer o lugar tão estável do saber professoral e da imaturidade do infante. Professora e Menino fugiam para o espaço em branco.

Leitores, não se apressem em preencher o branco. Branco, no chão da promissora escola, está longe de ser vazio ou cor neutra passível de se inscrever em metas desesperadas por qualificação. Com Guimarães Rosa temos pistas de que o que faz o Menino é o 'não sabido'. O espaço em branco não é papel carente de escrita confiante no futuro certo. Papel em branco é a própria escrita. Escrita de si, que vai se compondo não para saber, mas para afirmar que no corpo, com o corpo, seus pesos e aranhões, vamos tecendo uma prosa infinita.

Escrever, então, passa a ser uma responsabilidade terrível. Invisivelmente, a escrita é convocada a desfazer o discurso no qual, por mais infelizes que nos acreditamos, mantemo-nos, nós que dele dispomos, confortavelmente instalados. Escrever, desse 
ponto de vista, é a maior violência que existe, pois transgride a Lei, toda lei e sua própria lei. (BLANCHOT, 2010, p.9).

Menino e professora vão tateando o chão. Não somente com as mãos e seus sedentos dedos repletos de indicadores identitários. O tato é com o corpo todo, com a pele, com a coxa. Aliás, coxa que o Menino já deixava engrossar, pois queria músculos, assim aprendera que eram os meninos. Doía um pouco essa coisa de se muscular, pois o Menino não sabia o que era ser menino. Só queria.

Já as pontas dos dedos iam se arranhando com o contato com aquele enrugado piso escolar. Nas pontas dos dedos já se confundiam as marcas das identidades. Nem o mais atento policial conseguiria resgatar as marcas daquelas digitais que se borravam com pequenos materiais deixados pelos longos anos daquela escola.

Eles descobriam o chão, brincavam com pedaços de histórias como que fossem bons entulhos largados num canteiro de obras. Walter Benjamin (1997) nos alerta para a tolice pedante que são materiais educativos apropriados para crianças. Objetos que carregam marcas de especulações pedagógicas e de uma psicologia adulta. Adulta, madura são adjetivações trazidas a texto para lembrar que o desenvolvimento humano entendido como trânsito entre idades carrega uma verdade evolutiva que pode estar apagando o caráter da experimentação de não se saber, de não querer ser algo no futuro, mas algo por vir.

O supervisor se encontrou com o lugar do corpo indesejado, abjeto e terrivelmente útil como exemplo do que acontece com transgressores. Os diplomas não garantiam um lugar tão diferente assim de Samuel e da professora, dejetos de um sistema normativo. Mas, mesmo sem querer, o encontro com o chão mudou a perspectiva da escola. A escola não sabia sobre homossexualidades e precisava de informações? Ou talvez embarcasse no jogo identitário, que tenta simplificar e estratificar a vida em modos de existência pré-delimitados, demarcados para nosso uso?

Como deslocar o olhar pedagógico, tão viciado em se propor como verdade sobre os sujeitos e sobre o mundo? No que implica partir do lugar do chão sujo, ignorado e abjeto para produzir incômodos, estranhamentos pedagógicos e desejo coletivo por aprendizagem? (LOURO, 2001). Se o prazer não cabia no almoço do refeitório, encontrou passagem nas ranhuras do empoeirado pátio de cimento, cheio de marcas de giz de desenhos que a equipe de limpeza insiste em faxinar. A escola está ali, no presente, construindo, rompendo e costurando caminhos possíveis. 
Assim, mais do que uma polaridade de partes ou concepções educacionais, entender a escola como espaço "escoriado, dilacerado, aberto. Desagregado, estilhaçado pela história, um chão que berra" (DIDI-HUBERMAN, 2013, p. 109) é pedir passagem para que outros modos de se entender criança possam se afirmar. Nesta perspectiva, não se vislumbram futuros e presentes adultos saudáveis e coerentes, mas crianças menos preocupadas em imitar o mundo dos 'maduros'. O brinquedo ensaia uma nova e brusca relação entre si.

Com isso, as crianças criam elas mesmas o seu mundo de coisas, um pequeno mundo dentro do grande. Não se devem perder de vista as regras desse pequeno mundo das coisas quando se pretende criar especificamente para as crianças sem deixarmos que a nossa atividade, com tudo aquilo que são os seus requisitos e instrumentos próprios, encontre o caminho que leva a elas, e só esse. (BENJAMIN, 2013, p.16).

A escola, sempre em reforma, tinha muito desses pedaços de objetos residuais deixados pelas suas apostas redentoras de mudanças. Menino e professora, já não se sabem o certo quem eram, experimentavam cada pedacinho de chão, cada espacinho perdido da escola. Encontravam-se com os materiais educativos esquecidos no meio de uma massa de pó.

Rodopiavam, queriam o conforto da mobilidade. Jogavam os dois, faziam arte. Longe, bem longe dos maduros materiais escolares e princípios pedagógicos feitos por adultos para ensinar crianças a pensar. A professora borrada pelo jogo-criança, o supervisor que tem a carne exposta e o Menino marcado por arranhões menos totalitários iam se inscrevendo na pedagogia que quer ser nada. Educação que se quer no jogo.

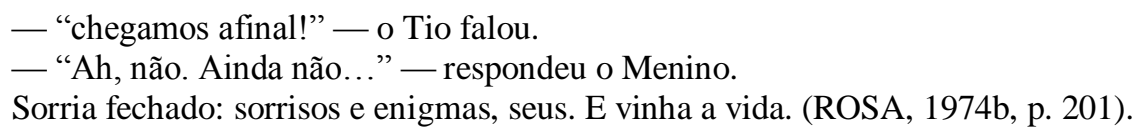

\section{Referências}

BENJAMIN, W. Canteiro de obra. In: Rua de mão única. São Paulo: Brasiliense. 1995. p.18-19.

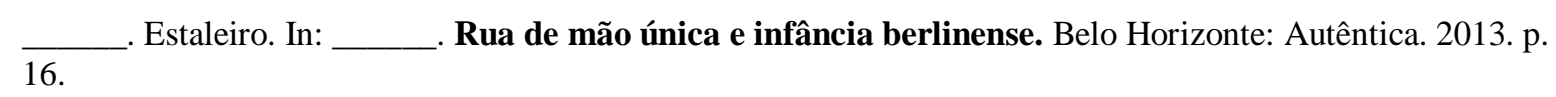

BLANCHOT, M. A conversa infinita: a palavra plural. São Paulo: Escuta. 2010.

BRASIL. [s.d]. Lei $\mathbf{n}^{\mathbf{0}}$ 13.005, de 25 de junho de 2014. Disponível em: <http://www.planalto.gov.br/CCIVIL_03/_Ato2011-2014/2014/Lei/L13005.htm>. Acesso em: 23 ago. 2014.

DIDI-HUBERMAN, G. Cascas. In: INSTITUO MOREIRA SALLES. Serrote, $\mathrm{n}^{\circ} 13$. Rio de Janeiro: Instituto Moreira Salles, 2013, p. 99-133.

\section{POLÊM!CA | Revista Eletronica da Uej}


FOUCAULT, M. História da Sexualidade I: A vontade de saber. Petrópolis: Vozes, 1988.

IBGE. Perfil dos municípios brasileiros 2013. Disponível em:

<http://www.ibge.gov.br/home/estatistica/economia/perfilmunic/2013/default.shtm>. Acesso em: 16 mar. 2015.

LOURO, G, L. Teoria Queer: uma política pós-identitária para educação. Revista de Estudos Feministas, Florianópolis, v. 9, n. 2, p. 541-553, ago. 2001.

ROSA, G. As margens da alegria. In: Primeiras estórias. São Paulo: Civilização Brasileira, 1974a, p. 21-26.

Os cismos. In: Primeiras estórias. São Paulo: Civilização Brasileira, 1974b, p. 193-201.

SILVA, Tomaz Tadeu. Identidade e Diferença: Impertinências. Educação \& Sociedade, vol. 23, n.79, ago. 2002, p. 65-66.

Recebido em: 21/07/2015.

Aceito em: 23/10/2015. 